\title{
E-Commerce Curriculum Design Based on Distance Learning System
}

\author{
http://dx.doi.org/10.3991/ijet.v10i3.4598 \\ Congwei LI \\ Jinhua Polytechnic, Jinhua, China
}

\begin{abstract}
Distance learning system, as an important teaching means, demonstrates the gradual maturity and penetration of technology in the teaching practice of disciplines. This paper proposes an application of distance learning for an e-commerce curriculum. First, this paper forwards the implication of distance learning system and its superiority, and further the system based on the SNS social interaction mode to address the limitations of existing distance learning systems by the advantages of the SNS social interaction mode. Second, the distance learning system is applied for an e-commerce curriculum. In accordance with the requirements of an e-commerce curriculum, the distance learning system and user frameworks are designed. The experiment adopts multiple evaluation indexes, and then utilizes the linear regression evaluation methodology for result assessment. Result shows that students in the experimental group under the distance learning system teaching mode are superior to students in the control group in terms of various indexes and comprehensive evaluation.
\end{abstract}

Index Terms-SNS social interaction mode, distance learning system, e-commerce

\section{INTRODUCTION}

Over the past 10 years, China's economy has been in the stages of high-speed development. As the Internet technology improves, China's economy enters the information economy era, and a large demand for e-commerce talents is promoted. To satisfy the demand for talents, universities and colleges in China have developed an ecommerce curriculum. However, e-commerce is an interdisciplinary curriculum that requires students to master computer networking technology, marketing, international trade, economic management, and business administration. Thus, e-commerce teaching requires the understanding of e-commerce technology and commercial knowledge that necessitate intensive study from students and teaching expertise from teachers.

In the U.S., e-commerce curricula appear in the form of e-commerce topics. Research contents of various famous universities involve comprehensive applications of computer and economic management. In 1998, Carnegie Mellon University established the E-commerce College. In 1999, the first master's degree in e-commerce was offered. In terms of curriculum construction, the U.S., represented by the enterprise mode, self-adjusts its teaching contents and curriculum categories according to market demand [1]. Britain regards occupation, applicability, and local character as features of the curriculum result. Germany proposes a "dual system" curriculum structure to meet social reputation and enterprise benefit [2]. Archana Patro assessed the level of planning for adopting standards and assisted management schools and universities in their decisions regarding adopting International Financial Reporting Standards (IFRS) in the Indian e-commerce curriculum [3]. Elizabeth Ocampo-Gómez addressed ethical concerns possibly rooted in the university program for the Mexican accounting profession [4]. David Gilbertson suggested flexible alternatives for Public Company Accounting Oversight Board (PCAOB) into the curriculum to allow teachers to more effectively include audit regulation in the classroom and achieve a high level of student comprehension and learning on the topic [5]. Carla L. Wilkin reported successful results from a case study of a student-centered, research-led, and problem-based learning task that was incorporated into the curriculum of an Accounting Information Systems subject [6]. However, with the late start of e-commerce study in China, several problems exist, such as the less number of professional talents involved in e-commerce in various disciplines, old curriculum content, unreasonable curriculum arrangement, single teaching modes, methods, and means, and poor teaching links [7]. Thus, on the one hand, the demand for graduates specializing in e-commerce exceeds supply; on the other hand, a large number of enterprises cannot find e-commerce talents. To solve these problems, many scholars have conducted various studies. Sun Hong [8] proposed the combination of e-commerce knowledge and methods with professional applications and the launch of studies and training for individuals to assimilate ecommerce knowledge and skills. Xiong Yuning [9] proposed to establish a three-dimensional teaching mode and interactive mechanism of e-commerce interactive curriculum to mobilize the learning initiative of students and increase teaching quality. In addition, a number of studies have been conducted on e-commerce simulation systems [10], practical teaching modes [11], and e-commerce process systematization [12].

Although many innovations in teaching contents and teaching methods of the e-commerce curriculum exist, this curriculum cannot fully motivate the learning initiative of students because of strong theoretical property. To further mobilize the enthusiasm of students, many scholars propose the combination of the Internet innovative teaching mode and Internet-based learning systems [13]. Highspeed development of the Internet brings rich experiences for users, particularly young people. The traditional Internet learning mode cannot stimulate the learning initiative of students.

The present study combines the advantages of distance learning systems, innovatively uses the SNS mode in the distance learning system, and further applies the distance learning system based on the SNS mode to stimulate the interests of students for the e-commerce curriculum. 
Meanwhile, the strong propagation effect of SNS is utilized to increasingly benefit teaching.

\section{DISTANCE LEARNING SYSTEM}

\section{A. Distance learning}

Distance learning refers to learner-centered, non-faceto-face teaching activity in a network environment. Guided by modern educational thought and theoretical direction of learning, distance learning fully utilizes educational network functions and abundant network education resource superiority to provide network teaching and learning environment for educators and learners and to convey digital contents. Compared with traditional learning methods, distance learning has five advantages: (1) it breaks through learning space limitation; (2) it breaks through traditional school walls and initiates learning mode changes; (4) it breaks through traditional teaching media and mobilizes multi-media for teaching; and (5) it breaks through the form unity of education and teaching information communication, contributes to educational resource sharing, and improves education efficiency and benefit [14].

\section{B. SNS mode}

SNS refers to Social Networking Services[15]. SNS is an Internet application service that helps people in establishing their social networks. The theoretical bases of SNS include "six-degree theory" and "150" rule [14]. SNS development has included the single friend-making function based on "six-degree theory" and diversified and entertained friend-making and SNS marked by "real friendship". At present, popular SNS includes Xiaonei and QQ alumnus, with their user scales reaching 235 million, which indicate a huge influence.

As seen from the hierarchy of needs, SNS meets the needs of users in terms of emotion and sense of belongingness, the need to gain self-respect and others' respect, and the need for self-actualization. The SNS communication process is complex and fuses realistic interpersonal and organizational communication functions. With its use of mass communication technology, SNS has a number of mass communication functions. These functions are fused and mingled and are therefore difficult to distinguish with one another.

Modern undergraduates seek to dominate over others and aim to show their ideas and capabilities and gain the approval of others. SNS provides a good platform for these undergraduates, thus its popularity. The application of SNS in teaching activities is highly acceptable to students and can easily motivate them. While SNS has communication features that are necessary in teaching activities, its application in teaching activities is feasible.

\section{SNS-based distance learning system}

A traditional distance learning system is illustrated in figure 1 . The advantage of this system is the collection of learning resources for users. However, its shortcoming is the lack of interactions among users and the limited connection between users and resources. Thus, mobilizing the lasting interest of users is difficult. In this manner, distance learning systems cannot achieve their purpose.

Traditional distance learning systems have poor interactivity, while SNS has good interactivity and strong viscosity for users. Thus, this study proposes a SNS-based distance learning system, as shown in figure 2 . The new sys-

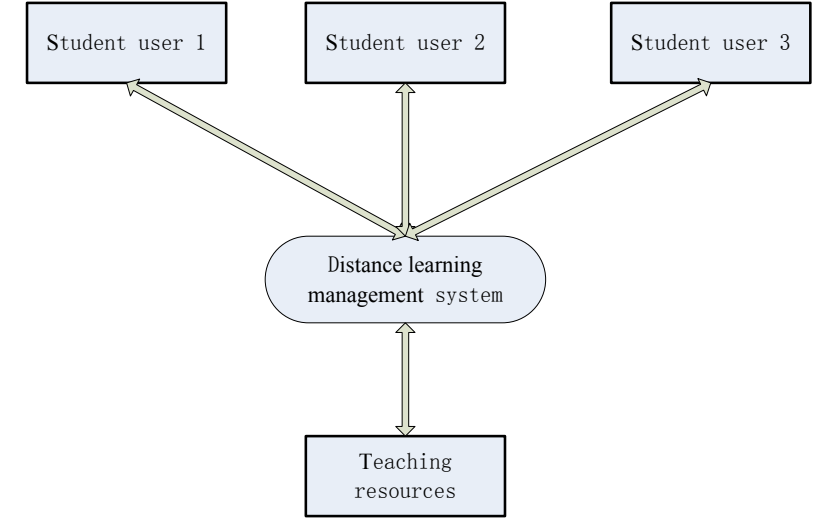

Figure 1. Traditional distance learning system

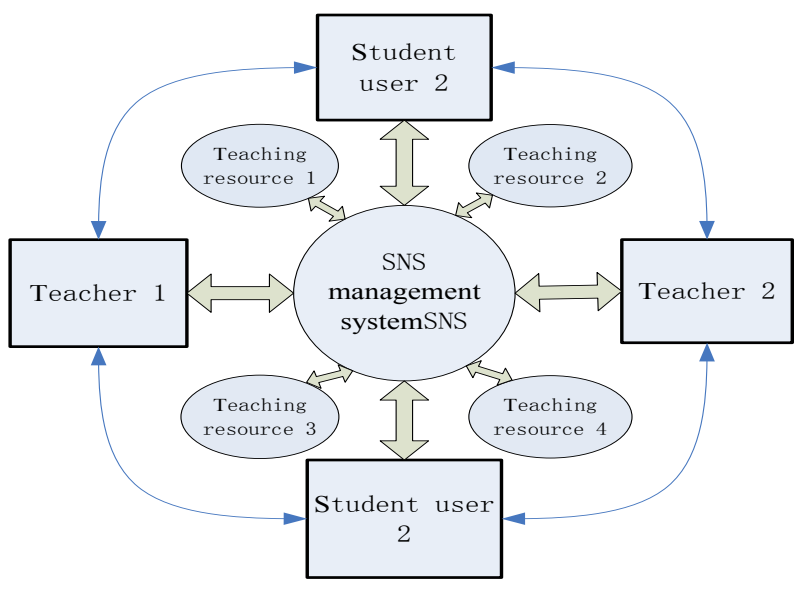

Figure 2. SNS-based distance learning system

tem retains the resource concentration superiority of a traditional distance learning system. Meanwhile, the original management system is replaced by the SNS management system to enhance interactions of the entire system.

In the SNS-based distance learning system, the SNS management system is the core. Besides the management of educational resources and users, convenient interactions among each element of the system remain necessary. Existing SNS websites provide service contents as personal homepage, blog, sharing, personal file, application, personal center, photo album, and gifts for users. These service contents carry a feature for recreation. In view of the teaching characteristics of distance learning systems, service contents (figure 3 ) at the user layer are modified. Teaching-related services are added largely, and recreational contents are reserved properly. In the personal homepage, except the traditional curriculum study, project practice is added. Besides, the practice platform is provided for students. More importantly, user interaction can be enhanced by the sharing and interactive systems. In the personal system, personalized services are provided for users. For their reference, users may reserve the contents in the previous four units according to their preference.

In the aspect of system resources, unlike the single mode of the traditional learning system, the interaction between users and resources is added in the new system. Thus, a dual mode is formed. Aside from browsing and downloading original teaching resources, users may upload relevant resources to the system, thereby enriching the system resources. The distance learning system interfaces are shown in figure 4 and 5 . 
PAPER

E-COMmerce CurRiculum Design BASED on Distance LeARning System

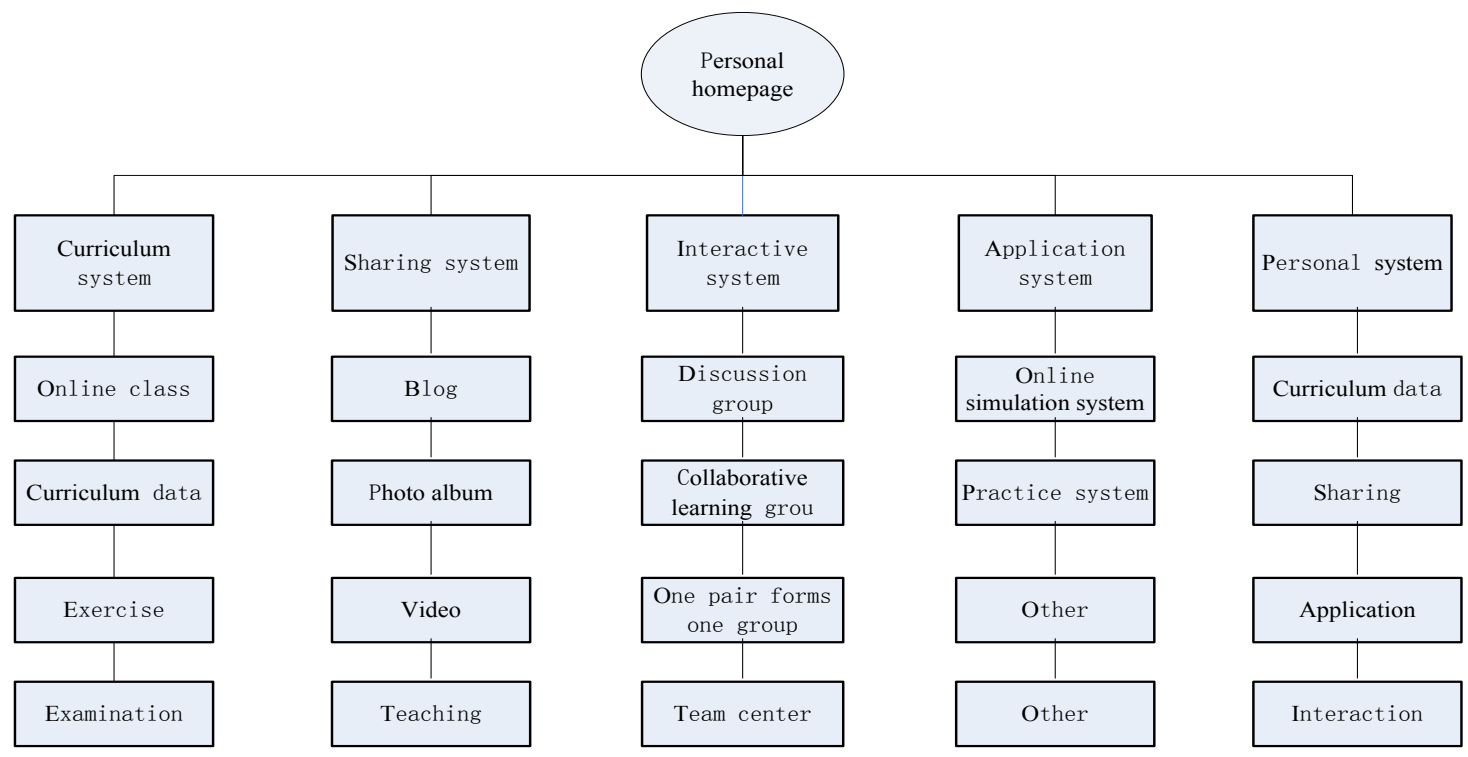

Figure 3. Composition of a personal homepage

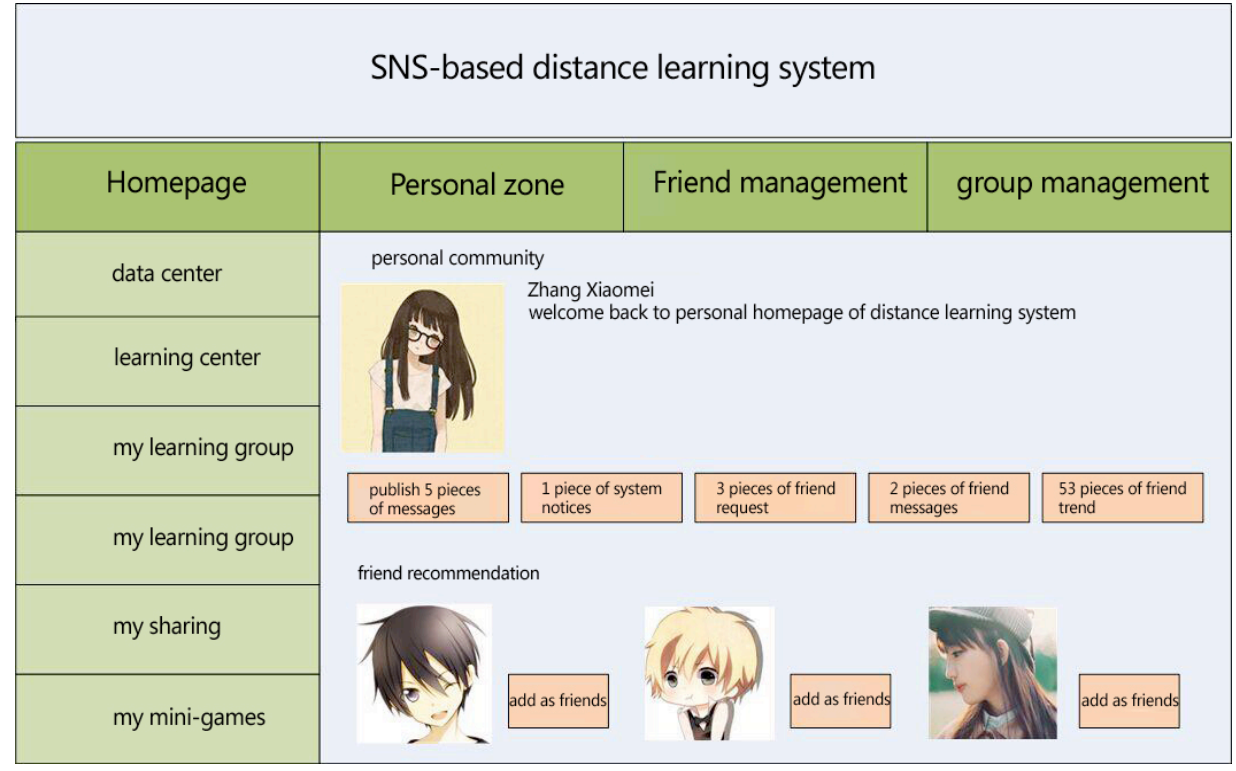

Figure 4. Distance learning system interface 1

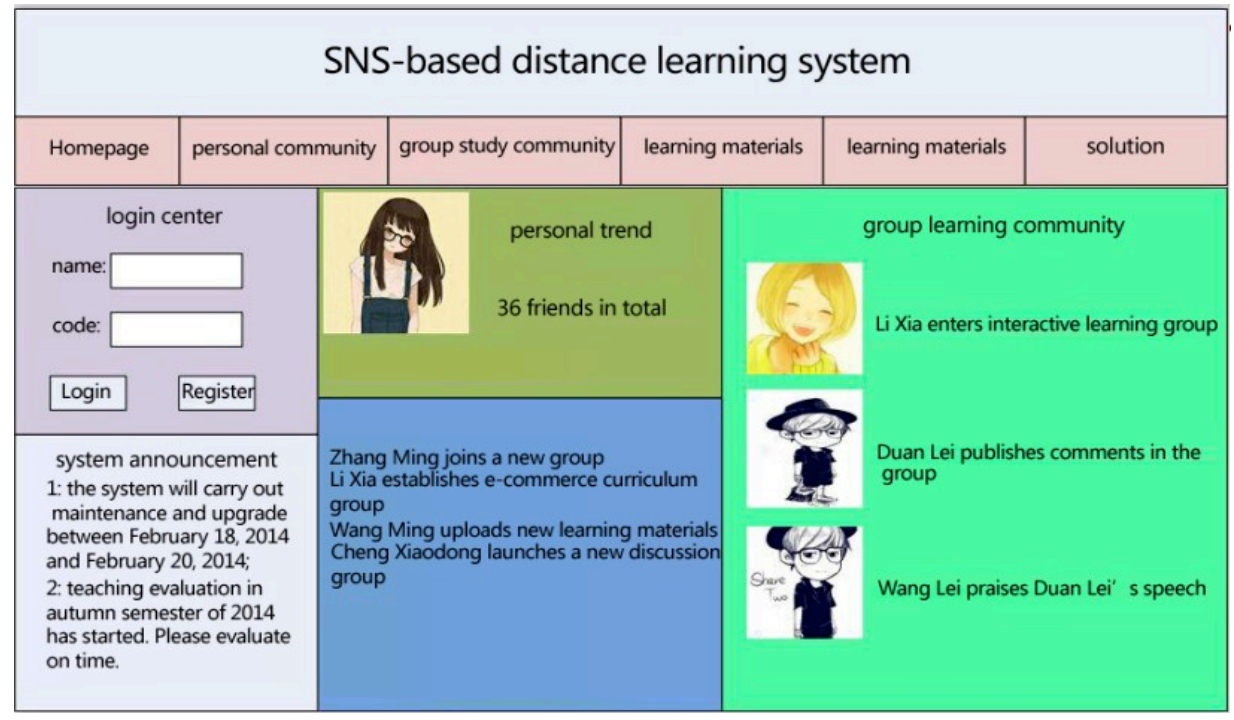

Figure 5. Distance learning system interface 2 


\section{APPLICATION OF THE DISTANCE LEARNING SYSTEM} IN THE E-COMMERCE CURRICULUM

\section{A. Experimental subject}

To verify the application effects of the distance teaching system in an e-commerce curriculum, two classes comprising 60 students who specialize in e-commerce and entered the university in 2011 were selected randomly as objects of the study. A total of 30 students from Class 1 served as the experimental group, while 30 students from Class 2 served as the control group. The students in the control group were taught in the traditional teaching mode, whereas the students in the control group were taught in the distance teaching mode.

B. Experimental period, class hour setting, and arrangement

Experiment teaching for two semesters was conducted during the academic year of 2013 to 2014. Teaching duration of the e-commerce curriculum in the traditional teaching mode was 64 class hours each semester, which include 32 class hours of theory study and 32 class hours of practice. The teaching duration in the distance learning mode was not fixed. Theory study was 32 class hours. However, students may determine the teaching duration themselves, depending on the time they required to complete the exercises, tests, and practice according to requirements of teaching program.

\section{Evaluation methodology}

In the traditional teaching mode, the examination method was used to evaluate student learning. While undertaking the examination, students may purely pursue high scores and ignore other abilities that they may have acquired during the learning process. With the aim to contrast the traditional evaluation mode, evaluation indexes and method have been innovated.

For the evaluation indexes, cultivating the all-round development of the students is the objective. We consider the comprehensive quality of the students and the natural science and engineering curricula in establishing evaluation indexes and assessment forms:

(1) A test was administered for the experimental and control groups after the teaching link was completed. The total score is 100 . The test comprised a written examination (description of the nouns and case analysis) and curriculum practice (project simulation and project practice). Each part accounts for 50 points. All students participated in the test. The results were collected and analyzed after the test. SPSS was used for the statistical analyses.

(2) The teacher evaluated the teaching process (evaluation indexes included interaction between teaching and learning, classroom atmosphere, and teaching feedback) after the class. The assessment of experts and scores were combined to identify the application effects of distance teaching in an e-commerce curriculum. The total score of each index is 100. The mean value of each evaluation index produced the final score.

(3) Each student evaluated the teaching process (evaluation indexes included learning interest, teaching form, teaching means, and interaction between the teacher and students) to identify the degree of acceptance of the students to the different teaching modes. The total score of each index is 100 . The mean value of each evaluation index produced the final score.

\section{RESUlTS}

After the two-semester curriculum was completed, the control and experimental groups were assessed from three aspects: test score, teachers' evaluation, and students' evaluation. The linear regression model was used to comprehensively rate the experimental results. The general experimental results are shown in Table 1.

The overall experimental results show that the experimental group who underwent the distance teaching mode had superior scores compared with those of the control group who underwent the traditional teaching method. For the test scores, the score of the experimental group was higher than that of the control group, which indicates that the learning and ability of students to perform well in examinations improved under the distance learning system. For the two indexes, namely, teachers' and students' evaluations, the score of the experimental group was evidently higher than that of the control group. The largest difference was almost 20 points. This result shows that the teaching effect of the distance teaching mode is superior compared with that of the traditional teaching mode. In addition, the acceptability of distance teaching is more superior and the degree of knowledge assimilation is higher among the students who underwent the distance teaching mode than those who underwent the traditional teaching mode. The detailed analyses are as follows:

(1) For the test assessment, students in the control group generally expressed difficulty in the curriculum practice because of the exclusive focus of the teacher on theoretical knowledge in the traditional teaching process. Meanwhile, each curriculum of e-commerce is distinct, and students lack the ability to solve actual problems and comprehensively apply knowledge of multiple curricula. Students in the experimental group generally expressed moderate difficulty in the assessment. They were able to participate in project practice under the distance learning system. While the SNS mode is common to the lives of students and integrates recreation and learning, the learning initiative of students is considerably mobilized. Interactive learning effect is obvious. The learning potential of students is fully harnessed.

The detailed scoring results listed in Table II indicate that for objective questions, the experimental group differs slightly from the control group. However, in subjective questions and project practice in particular, the performance of the experimental group is much superior compared with the control group. Such phenomenon indicates that students in the experimental group can flexibly utilize their knowledge and effectively apply what they have learned in solving specific problems.

(2) In terms of teachers' evaluation, the teacher reflected that students in the experimental group can quickly assimilate concepts and can flexibly apply knowledge in discussions and exchanges. Distance learning systems considerably save the time for writing on the blackboard by the teacher. Further, the degree of intensity of the teachers' load is reduced, and teaching efficiency is improved. The promotion of teaching efficiency enables the teacher to sufficiently guide students in completing their practical reports, actively address problems in practice, and discuss solutions with students. In the traditional teaching process, teaching materials could not be reutilized. The teacher therefore spends time on repeated labor. In the index of the teachers' evaluation, each score of the 
TABLE I.

COMPARISON OF THE OVERALL EXPERIMENTAL RESULTS

\begin{tabular}{|c|c|c|c|c|}
\hline Group & Test score & Teachers' evaluation & Students' evaluation & Comprehensive score \\
\hline Control group & $51.97(\mathrm{P}=0.0065)^{*}$ & $52.14(\mathrm{P}=0.0047)^{*}$ & $45.31(\mathrm{P}=0.0043)^{*}$ & 49.68 \\
\hline Experimental group & 74.39 & 67.27 & 70.16 & 69.72 \\
\hline
\end{tabular}

TABLE II.

EVALUATION OF THE TEST SCORES

\begin{tabular}{|c|c|c|c|c|c|}
\hline Group & $\begin{array}{c}\text { Explanation of } \\
\text { nouns }\end{array}$ & Case analysis & Project simulation & $\begin{array}{l}\text { Project prac- } \\
\text { tice }\end{array}$ & $\begin{array}{c}\text { Comprehensive } \\
\text { evaluation }\end{array}$ \\
\hline Control group & $15.23(\mathrm{P}=0.028)^{*}$ & $21.39(\mathrm{P}=0.014)^{*}$ & $12.28(\mathrm{P}=0.021)^{*}$ & 8.29 & 56.84 \\
\hline Experimental group & 15.39 & 22.16 & 22.39 & 18.72 & 76.19 \\
\hline
\end{tabular}

* $\mathrm{P}<0.05$, comparison with the experimental group

TABLE III.

RESULTS OF TEACHERS' EVALUATION

\begin{tabular}{|c|c|c|c|c|c|}
\hline Group & $\begin{array}{l}\text { Interaction between } \\
\text { teaching and learning }\end{array}$ & $\begin{array}{c}\text { Classroom atmos- } \\
\text { phere }\end{array}$ & Teaching feedback & $\begin{array}{c}\text { Experts' } \\
\text { evaluation }\end{array}$ & $\begin{array}{c}\text { Comprehensive } \\
\text { evaluation }\end{array}$ \\
\hline Control group & $43.21(\mathrm{P}=0.021)^{*}$ & $55.89(\mathrm{P}=0.035)^{*}$ & $48.36(\mathrm{P}=0.017)^{*}$ & 44.19 & 48.97 \\
\hline Experimental group & 72.39 & 80.19 & 76.24 & 70.25 & 74.61 \\
\hline
\end{tabular}

* $\mathrm{P}<0.05$, comparison with the experimental group

TABLE IV.

RESULTS OF STUDENTS' EVALUATION

\begin{tabular}{|c|c|c|c|c|c|}
\hline Group & $\begin{array}{c}\text { Learning } \\
\text { interest }\end{array}$ & Teaching form & Teaching means & $\begin{array}{l}\text { Interaction between the } \\
\text { teacher and students }\end{array}$ & $\begin{array}{c}\text { Comprehensive } \\
\text { evaluation }\end{array}$ \\
\hline Control group & $53.47(\mathrm{P}=0.017)^{*}$ & $50.36(\mathrm{P}=0.032)^{*}$ & $40.72(\mathrm{P}=0.038)^{*}$ & 45.79 & 46.82 \\
\hline Experimental group & 80.39 & 72.18 & 69.13 & 82.19 & 75.78 \\
\hline
\end{tabular}

TABLE V.

STUDENTS' EMPLOYMENT STATUS

\begin{tabular}{|c|c|c|c|c|}
\hline Group & $\begin{array}{c}\text { Proportion of the number of } \\
\text { students starting up businesses } \\
(\%)\end{array}$ & $\begin{array}{l}\text { Proportion of the number of students } \\
\text { looking for jobs related to their special- } \\
\text { ization (\%) }\end{array}$ & $\begin{array}{l}\text { Employers' } \\
\text { satisfaction }\end{array}$ & $\begin{array}{l}\text { Students' employment } \\
\text { satisfaction score }\end{array}$ \\
\hline Control group & 2.39 & 52.76 & 62.13 & 55.38 \\
\hline Experimental group & 10.56 & 84.71 & 79.24 & 74.27 \\
\hline
\end{tabular}

experimental group emerged superior compared with that of the control group. Results of the teachers' evaluation are shown in Table III.

(3) In the aspect of students' evaluation, the experimental group who underwent distance learning and who were evaluated based on the teaching method, content, and effect were adjusted to improve the rate of cramming under the previous mode. Students generally expressed that distance learning system could deepen understanding of concept and contents and increase teaching efficiency. In the teaching process, the learning initiative of students was stimulated enormously. Interactive learning effect was obvious. Most students preferred novel, heuristic, and new teaching classroom. These approaches could help teachers improve. However, in the actual implementation process, because some students lacked self-control, they spent much time on activities unrelated to their study under the distance learning system. Although the teacher can manage the class, the effect was not obvious. The experimental result was affected partly. Results of students' evaluation are shown in Table IV.
To further test the effects of the distance learning system, employment status of the students in the experimental and control groups was investigated, and comparison was carried out from three aspects: employment type, employers' satisfaction, and students' employment satisfaction. The results are shown in Table V and Fig. 8. The results indicate that students in the experimental group are much better than those in the control group in terms of the proportion of business startup and major association and in terms of knowledge mastery and application. Meanwhile, students in the experimental group have high market satisfaction, and students' satisfaction is also high.

\section{CONCLUSIONS}

1) Distance learning systems have some breakthroughs, including the provision of access to various teaching resources in the network based on the traditional teaching mode and store various teaching resources on the network. Moreover, teaching materials can be reutilized, which saves time for writing on the blackboard by teachers, reduces teachers' work intensity, and improves teaching efficiency. Students may log into a distance learning sys- 
tem anytime and anywhere to enhance their recall of concepts and understanding.

2) SNS-based distance teaching mode has some breakthroughs compared with the traditional distance learning system. The SNS-based distance learning system retains the advantages of having a concentration of teaching resources, utilizing SNS interactivity, promoting deep interactions among students and between students and teachers, and providing access to teaching resources that can stimulate the learning interest of students. Thus, the distance teaching mode generates strong viscosity for students, allowing them to assimilate knowledge easily.

3) As shown in the experimental results, the experimental group is much better than the control group in terms of school assessment scores and graduation status. Therefore, the application of the SNS-based distance learning system for an e-commerce curriculum is feasible.

4) SNS has its strong points. The application of SNS in teaching activities motivates many students and produces expected effects. However, because of the recreation offered by SNS, some students disregard their studies under the distance learning system. This problem should be addressed in follow-up studies.

\section{REFERENCES}

[1] Deng S M, Yuan Y Z, "Comparative analysis of development status of Chinese and American modern distance education." Distance Education in China, vol. 26, no. 9, pp. 28-29, September 2009.

[2] Dimitrios Buhalis, Maria Cristina Licata, "The future tourism intermediaries." Tourism Management, vol. 23, no. 5, pp. 207-220, May 2002. http://dx.doi.org/10.1016/S0261-5177(01)00085-1

[3] Archana Patro, V.K. Gupta, "Adoption of International Financial Reporting Standards (IFRS) in Accounting Curriculum in IndiaAn Empirical Study." Procedia Economics and Finance, vol.2, pp. 227-236, February 2012, http://dx.doi.org/10.1016/S22125671(12)00083-4

[4] Elizabeth Ocampo-Gómez, Juan C, “Ortega-Guerrero. Expanding the perspective and knowledge of the accounting curriculum and pedagogy in other locations: The case of Mexico." Critical Perspectives on Accounting, vol. 24, no. 2, pp. 145-153, March 2013, http://dx.doi.org/10.1016/j.cpa.2012.07.002
[5] David Gilbertson, Terri Herron, "Including audit regulation in the accounting curriculum." Research in Accounting Regulation, vol. 26, no. 1, pp. 118-131, January 2014, http://dx.doi.org/10.1016/ j.racreg.2014.02.013

[6] Carla L. Wilkin, "Enhancing the AIS curriculum: Integration of a research-led, problem-based learning task." Journal of Accounting Education, vol. 32, no. 2, pp. 185-199, February 2014. http://dx.doi.org/10.1016/j.jaccedu.2014.04.001

[7] Yang L, Su X K, "Exploration and analysis of e-commerce course teaching reform." Journal of Zhengzhou Institute of Aeronautical Industry Management (Social Sciences), vol. 29, no. 5, pp. 151153, May 2010.

[8] Hong S, Li S, "Study on teaching design combining e-commerce curriculum and major." Vocational Education, vol. 5, no.8, pp. 249-251, August 2012.

[9] Xiong Y N, Lan H, Jin L, "Research on three-dimensional teaching mode of e-commerce and interactive learning mechanism." Journal of Higher Education (Chengdu), vol. 13, no. 1, pp. 121122, January 2011,.

[10] Sun L Y, "Study and construction of e-commerce simulation system.” Jinan: Shandong Normal University, 2003.

[11] Zhan Z Q, "Innovative study on practical teaching mode of ecommerce." Henan Education (specialized course teaching), vol. 3, no. 2, pp. 36-37, February 2012.

[12] Zheng S Y, "E-commerce curriculum design based on working process systematization." Journal of Chongqing Vocational \& Technical Institute, vol. 18, no. 6, pp. 150-152, June 2009.

[13] Jin H X, Liu G, "Conception of Internet-based e-commerce teaching system.” Journal of Shenyang College of Education, vol. 12, no. 2, pp. 69-72, February 2009.

[14] Yang X T, Wu B, Zhang J, "Study on SNS development strategy under six-degree separation degree." New West, vol. 8, pp. 42-43, August 2013.

[15] Liu Y N, Tang H, Zhao G F, "Campsna: A cloud assisted mobile peer to peer social network architecture." Journal of Digital Information Management, vol. 12, no.2, pp. 126-232, April 2014.

\section{AUTHOR}

Congwei LI is a Lecturer with Jinhua Polytechnic, Jinhua, 321007 China. His research interests include Ecommerce and information management (e-mail: licongwei33@yeah.net).

Submitted 23 March 2015. Published as resubmitted by the author 11 May 2015. 